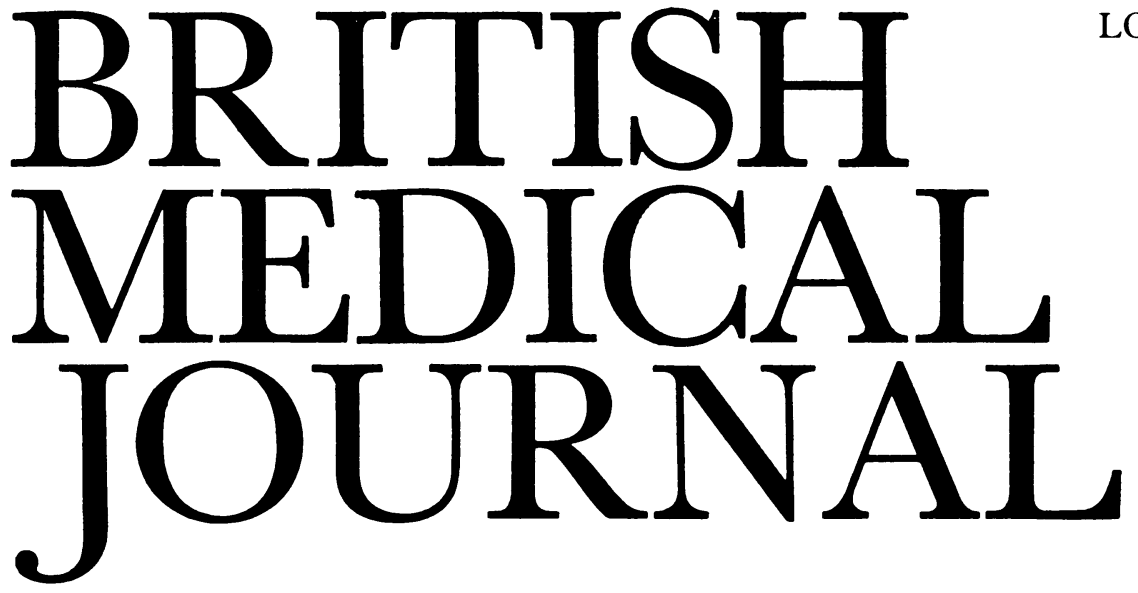

LONDON, SATURDAY 20 OCTOBER 1984

\title{
Hypertension in women: a separate case for treatment?
}

Men have higher risks than women of both death and morbidity from cardiovascular disease. This difference has been interpreted by some doctors as suggesting that a less interventionist approach is needed for the treatment of hypertension in women, no fewer than one third of general practitioners surveyed admitting to different treatment policies for the two sexes. ${ }^{1}$ Indeed, many of the big studies of intervention against risk factors for cardiovascular disease, whether hypertension alone or multiple risk factors, have looked at the effects on men only. ${ }^{2-5}$ What, therefore, should our policy be on the detection and treatment of hypertension in women?

Irrespective of definitions, the prevalence of hypertension is broadly the same in the two sexes, ${ }^{6}$ and the observed rise with increasing age is of the same extent. ${ }^{7}$ It is, however, very difficult to ascertain whether any recent changes have occurred in the relative prevalence. The rates of both diagnosis and treatment have increased at varying thresholds of blood pressure, rendering current surveys of the occurrence of hypertension difficult to interpret. Paradoxically, perhaps, this activity has had a greater impact on women. In the control ("reference") area in the North Karelia study the mean diastolic blood pressure fell in both sexes during the decade 1972 to $1982 .{ }^{8}$ The fall was larger in women $(6.4 v 4.2 \mathrm{~mm}$ $\mathrm{Hg}$ ). How much this was due to changes in diagnosis or to changes in factors predisposing to hypertension between the sexes is impossible to say.

Should there be a different threshold for treatment in the two sexes? To answer this we need to know whether the risks of major cardiovascular disease associated with hypertension -stroke and myocardial infarction-are related to sex. For stroke the overall incidence is similar in both sexes and with a pronounced increase with increasing blood pressure. Moreover, data from Framingham showed that the risks of stroke within the different blood pressure strata were also similar. ${ }^{7}$ The same is probably not true for myocardial infarction. Both fatal and non-fatal infarction at all levels of blood pressure are about two and a half times more common in men aged below 75.9 Thus the absolute risk at all levels of blood pressure is lower in women. ${ }^{10}$ Nevertheless, the rate of increase in risk with rise in blood pressure is not identical in the sexes: the Framingham data suggest that the slope is steeper in women, so that as blood pressures increase in the two sexes the risks begin to converge. ${ }^{11}$ Finally, the rise in absolute risk of electrocardiographic changes of ischaemia with increasing blood pressure is no higher in men. ${ }^{9}$

Differences in risk, however, cannot easily be translated into differences in response to hypotensive treatment. The data from published clinical trials are inconclusive. The Veterans studies, which included only men, showed a clear benefit in reduction in mortality from stroke in those with a diastolic blood pressure above $105 \mathrm{~mm} \mathrm{Hg.}{ }^{23}$ The United States hypertension detection and follow up programme compared two management regimens and found, confusingly, no benefit from the more intensive of these in white women but significant benefit in black women. ${ }^{12}{ }^{13}$ The Australian therapeutic trial of mild to moderate hypertension observed that the reduction in trial end points (fatal and non-fatal) was significant in men but not in women. ${ }^{14}$ Fewer end points were observed in the women who were treated $(24$ $v 36$ ), but the rates in both groups of women were less than half of those in the men in the study.

Other differences between men and women affect policies for the control of hypertension. Women have their blood pressure recorded more frequently, especially in general practice, reflecting current practices for prescribing oral contraception and in antenatal care.${ }^{15}{ }^{16}$ Conversely-perhaps because of differing perceptions of health education-the response rates to screening programmes for hypertension are often higher in men, ${ }^{17}$ though this finding is not universal. ${ }^{6}$ Hypertensive women tend to have a greater awareness of their condition than men. ${ }^{18}$ Whether this awareness differentially affects compliance to treatment and follow up is not known, but it remains a possible explanation for differences in outcome. Furthermore, other cardiovascular risk factors-for example, cigarette smoking-are associated with an increased risk in hypertensives. Thus the finding in community programmes such as the North Karelia study of a reduction in myocardial infarction in men but not in women ${ }^{19}$ may be explained by a combination of a reduction in cigarette smoking and a fall in mean blood pressure levels in men compared with little change in the already low rate of smoking in women. ${ }^{8}$

Against this background the effectiveness of such community based programmes of detection of hypertension and management in women should be assessed. In the first five 
years of the North Karelia study the mortality from cardiovascular disease in women aged 30 to 64 fell from 2.5 to $1 \cdot 7$ per 1000 person years compared with a fall from $7 \cdot 7$ to $6 \cdot 3$ in men. ${ }^{19}$ Mortality from stroke fell in women by half, and this is likely to be sustained by the continuing fall in blood pressure. ${ }^{8}$ A 12 year follow up study in Gothenburg of 1462 women found that $13 \%$ of women at baseline had untreated hypertension. ${ }^{20} 21$ The mean blood pressure level fell in these women during the first six years of follow up but had risen to baseline level by the twelfth year, despite $58 \%$ having treatment with specific drugs. These women, however, did not have an increased incidence either of stroke or of myocardial infarction compared with the normotensive women. Conversely, the women already having treatment at baseline, who were probably more severely hypertensive, did have a higher risk of cardiovascular events.

In summary, women with hypertension have the same risk of stroke as men but a lower risk of myocardial infarction. Given this observation, it is not surprising that no significant benefit of treatment of hypertension has been found in mildly hypertensive women. A rational policy, therefore, is to treat women with severe hypertension (diastolic blood pressure over $105 \mathrm{~mm} \mathrm{Hg}$ ) as vigorously as men but (pending any new findings from the Medical Research Council trial) not to give active treatment in mild to moderate hypertension. ${ }^{22}$ The presence of other risk factors-for example, cigarette smoking-should lead the doctor to consider intervention. Finally, as case finding is becoming an established part of general practice, at least for younger women, population based active screening programmes are unlikely to be cost effective. ${ }^{23}$

Alan J Silman

Senior Lecturer in Clinical Epidemiology,

London Hospital Medical College,

London E1 2AD

1 Hodes C, Rogers PA, Everitt MG. High blood pressure: detection and treatment by general practitioners. BrMed J 1975;ii:674-7.

2 Veterans Administration Co-operative Study Group on Antihypertensive Agents. Effects of (1) averaging 115 through $129 \mathrm{~mm} \mathrm{Hg}$. JAMA 1967;202:116-22.

3 Veterans Administration Co-operative Study Group on Antihypertensive Agents. Effects of treatment on morbidity in hypertension: results in patients with diastolic blood pressure averaging 90 through $114 \mathrm{~mm} \mathrm{Hg}$. $f A M A$ 1970;212:1143-52.

4 Multiple Risk Factor Intervention Trial Research Group. Multiple risk factor intervention trial. Risk factor changes and mortality results. JAMA 1982;248:1465-77.

5 Rose G, Tunstall-Pedoe HD, Heller RF. UK heart disease prevention project: incidence and mortality results. Lancet 1983;i:1062-6. 1974; iii:60-3.

7 Kannel WB, Wolf PA, Verter J, McNamara P. Epidemiologic assessment of the role of blood pressure in stroke. The Framingham study. JAMA 1970;214:301-10.

8 Puska P, Salonen JT, Nissinen A, et al. Changes in risk factors for coronary heart disease during 10 years of a community intervention programme (North Karelia project). Br Med $1983 ; 287: 1840-4$.

9 Miall WE, Chinn S. Screening for hypertension: some epidemiological observations. Br Med $\mathcal{J}$

1973:iii: $595-600$.
10 Society of Actuaries and Association of Life Insurance Medical Directors of America. Blood pressure study 1979. Chicago: Recording and Statistical Corporation, USA, 1980.

Kannel WB. Role of blood pressure in cardiovascular morbidity and mortality. Prog Cardiovasc Dis 1974;17:5-24.

12 Hypertension Detection and Follow-up Program Co-operative Group. Five year findings of the hypertension detection and follow-up program. I. Reduction in mortality of persons with high blood pressure, including mild hypertension. FAMA 1979;242:2562-71. hypertension detection and follow-up program. II. Mortality by race, sex and age. $J A M A$ 1979;242:2572-7.

14 Report by the Management Committee. The Australian therapeutic trial in mild hypertension. Lancet 1980;i:1261-7.

15 Barlow DH, Beevers DG, Hawthorne VM, Watt HD, Young AR. Blood pressure management at

screening and in general practice. Br Hear $\mathcal{F} 1977 ; 39: 7-12$.
$6 \mathrm{Heller} R \mathrm{RF}$, Rose G. Current management of hypertension in general practice. $\mathrm{Br}$ Med $\mathcal{J}$ 1977; ;:1442-4.

17 Hypertension Detection and Follow-up Program Co-operative

18 Tuomilehto J, Nissinen A, Salonen JT, Kottke TE, Puska P. Community programme for contro

18 Tuomilehto J, Nissinen A, Salonen JT, Kottke TE, Puska P. Community programme for control
of hypertension in North Karelia, Finland. Lancet $1980 ;$;i: $900-4$.
19 Salonen JT, Puska P, Mustaniemi H. Changes in morbidity and mortality during comprehensive community programme to control cardiovascular diseases during 1972.7 in North Karelia. $B$ Med F 1979; ii:11178-83.

20 Sigurdsson JA, Bengtsson C. Prevalence and management of arterial hypertension in a population sample of Swedish women. Scand F Soc Med 1981;9:41-7.

21 Sigurdsson JA, Bengtsson C, Lapidus L, Lindquist O, Rafnsson V. Morbidity and mortality in relation to blood pressure and antihypertensive treatment. A 12-year follow-up study of a population sample of Swedish women. Acta Med Scand (in press).
Medical Research

Medical Research Council Working Party on Mild to Moderate Hypertension. Randomised controlled trial

23 Bryers F, Hawthorne VM. Screening for mild hypertension: costs and benefits. $\mathcal{J}$ Epidemiol Community Health 1978;32:171-4.

\section{Children in a persistent vegetative state}

Karen Quinlan has been unconscious since she lapsed into coma on 15 April 1975. At first her life was maintained by mechanical ventilation, but in May 1976 a New Jersey court authorised her removal from the respirator. Contrary to expectations Karen did not die; eight years later she still lies in a New Jersey nursing home, unable to communicate or consciously to respond to her family, doctors, nurses, or environment. She is fed artificially and nursed night and day. She has attracted the attention from all parts of the world of doctors, philosophers, theologians, and lawyers who view her plight as a critical landmark in discussions on the uses and abuses of modern medical technology and the doctrine of ordinary and extraordinary means of prolonging life. Other patients have survived for much longer, but she is the best known example of the persistent vegetative state described recently as "a fate worse than death."

The term "persistent vegetative state" was suggested in 1972 to describe those patients with irreversible brain damage, usually from trauma or hypoxic ischaemia of the brain, and who on recovery from deep coma pass into a state of seeming wakefulness and reflex responsiveness but do not return to a cognitive sapient state. ${ }^{2}$ It is the result of destruction of the cerebral cortex or its integrating connections with sufficient preservation of the brain stem to sustain the vegetative functions-respiration, circulation, and so on. The persistent vegetative state must be distinguished from the better defined brain death (more correctly, brain stem death), where the patient does not survive once respiratory support is withdrawn. ${ }^{34}$ It must also be distinguished from other rare syndromes of prolonged unresponsiveness caused by selective damage to parts of the brain stem. ${ }^{56}$ Patients in the persistent vegetative state may survive almost indefinitely so long as they receive adequate nutrition, a high standard of nursing care, and are protected against infection.

The persistent vegetative state is being seen more often in children as improved techniques of resuscitation and intensive care have increased the chances of survival after severe trauma to the head or cardiorespiratory arrest. About $12 \%$ of adults who survive non-traumatic coma remain in a vegetative state. ${ }^{78}$ In children the incidence is probably less, but accurate estimates are difficult to make because of the heterogeneity of most studies and their small numbers. The type and duration of coma also influence the prognosis, which is poor after cardiorespiratory arrest, ${ }^{9}$ better after metabolic or encephalitic coma, ${ }^{10}$ and best of all after severe head injury. ${ }^{11}$ Children in coma are more unpredictable than adults, perhaps because their brains are at different stages of development and more resistant to various insults. This uncertainty should make us particularly cautious in making hasty judgments about prognosis. ${ }^{12}$

For their families children who remain in a persistent vegetative state are tragedies of great poignancy. For doctors and nurses they pose difficult moral and ethical dilemmas about the appropriate use of measures to prolong life when there is virtually no hope of a life of meaning and quality. For the health services they are a considerable burden on resources that might be used more appropriately for other patients. Criteria have been established for the determination of brain stem death and the withdrawal of respiratory support. ${ }^{13}$ We need to establish criteria for the persistent vegetative state and the appropriate action that should follow. 